\title{
OJInي
}

\section{AIAA 2003-3195 \\ Performance Analysis of a Cost-Effective Electret Condenser Microphone Directional Array}

William M. Humphreys, Jr.

Carl H. Gerhold

Allan J. Zuckerwar

Gregory C. Herring

Scott M. Bartram

NASA Langley Research Center

Hampton, VA 23681-0001

\section{9th AIAA/CEAS Aeroacoustics Conference \& Exhibit 12-14 May 2003 / Hilton Head, SC}




\title{
PERFORMANCE ANALYSIS OF A COST-EFFECTIVE ELECTRET CONDENSER MICROPHONE DIRECTIONAL ARRAY
}

\author{
William M. Humphreys, Jr.* \\ Carl H. Gerhold ${ }^{\dagger}$ \\ Allan J. Zuckerwar \\ Gregory C. Herring ${ }^{\S}$ \\ Scott M. Bartram ${ }^{\text {II }}$ \\ Aerodynamics, Aerothermodynamics, and Acoustics Competency \\ NASA Langley Research Center \\ Hampton, Virginia 23681-0001
}

\begin{abstract}
$\underline{\text { Abstract }}$
Microphone directional array technology continues to be a critical part of the overall instrumentation suite for experimental aeroacoustics. Unfortunately, high sensor cost remains one of the limiting factors in the construction of very high-density arrays (i.e., arrays containing several hundred channels or more) which could be used to implement advanced beamforming algorithms. In an effort to reduce the implementation cost of such arrays, the authors have undertaken a systematic performance analysis of a prototype 35-microphone array populated with commercial electret condenser microphones. An ensemble of microphones coupling commercially available electret cartridges with passive signal conditioning circuitry was fabricated for use with the Langley Large Aperture Directional Array (LADA). A performance analysis consisting of three phases was then performed: (1) characterize the acoustic response of the
\end{abstract}

\footnotetext{
*Research Engineer, Advanced Measurement and Diagnostics Branch, Senior Member AIAA.

'Senior Research Scientist, Aeroacoustics Branch, Member AIAA.

${ }^{\ddagger}$ Senior Research Scientist, Advanced Measurement and Diagnostics Branch.

${ }^{\S}$ Research Scientist, Advanced Measurement and Diagnostics Branch.

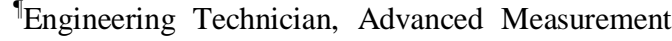
and Diagnostics Branch.

This material is declared a work of the U.S. Government and is not subject to copyright protection in the United States.
}

microphones via laboratory testing and calibration, (2) evaluate the beamforming capability of the electret-based LADA using a series of independently controlled point sources in an anechoic environment, and (3) demonstrate the utility of an electret-based directional array in a real-world application, in this case a cold flow jet operating at high subsonic velocities. The results of the investigation revealed a microphone frequency response suitable for directional array use over a range of $250 \mathrm{~Hz}-40 \mathrm{kHz}$, a successful beamforming evaluation using the electret-populated LADA to measure simple point sources at frequencies up to $20 \mathrm{kHz}$, and a successful demonstration using the array to measure noise generated by the cold flow jet. This paper presents an overview of the tests conducted along with sample data obtained from those tests.

\section{Nomenclature}

$\begin{array}{ll}D_{j} & \begin{array}{l}\text { free expansion jet nozzle } \\ \text { diameter, } \mathrm{ft}\end{array} \\ \hat{e} & \begin{array}{l}\text { array steering vector, } \\ \text { see eqn. (4) } \\ \text { frequency, } \mathrm{Hz}\end{array} \\ \hat{f} & \text { cross spectral matrix } \\ \hat{G} & \text { acoustic wave number, } \mathrm{ft}^{-1} \\ k & \text { number of steering locations } \\ K & \text { total number of array } \\ M & \text { microphones } \\ & \text { number of data blocks }\end{array}$




\begin{tabular}{|c|c|}
\hline$P(\hat{e})$ & $\begin{array}{l}\text { array output power for steering } \\
\text { vector } \hat{e}, \text { see eqn. }(5)\end{array}$ \\
\hline$P_{F}$ & $\begin{array}{l}\text { RMS pressure of fundamental } \\
\text { plus harmonic frequencies, } \mathrm{Pa}\end{array}$ \\
\hline$P_{H}$ & $\begin{array}{l}\text { RMS pressure of harmonic } \\
\text { frequencies, } \mathrm{Pa}\end{array}$ \\
\hline$S t$ & Strouhal number \\
\hline$r^{o}, r_{m}^{o}$ & $\begin{array}{l}\text { distance from source to } \vec{x}_{c} \\
\text { and } \mathrm{m}^{\text {th }} \text { microphone, } \mathrm{ft}\end{array}$ \\
\hline$r, r_{m}$ & distance from steering location \\
\hline & to $\vec{x}_{c}$ and $\mathrm{m}^{\text {th }}$ microphone, $\mathrm{ft}$ \\
\hline$R_{k}$ & $\begin{array}{l}\text { normalized array output of } \\
\text { reference LADA at } \mathrm{k}^{\text {th }} \\
\text { steering location }\end{array}$ \\
\hline$T H D$ & $\begin{array}{l}\text { total harmonic distortion, } \\
\text { percent, see eqn. (1) }\end{array}$ \\
\hline$T_{k}$ & $\begin{array}{l}\text { normalized array output of } \\
\text { ECM LADA at } k^{\text {th }} \\
\text { steering location }\end{array}$ \\
\hline$U_{j}$ & $\begin{array}{l}\text { free expansion jet exit velocity, } \\
\mathrm{ft} / \mathrm{sec}\end{array}$ \\
\hline$W\left(k, \vec{x}, \vec{x}^{o}\right)$ & $\begin{array}{l}\text { ideal array response, } \\
\text { see eqn. (7) }\end{array}$ \\
\hline$W_{s}$ & hamming window weighting \\
\hline$\vec{x}$ & Cartesian coordinate, $\mathrm{ft}$ \\
\hline$\vec{x}_{c}$ & array phase center, $\mathrm{ft}$ \\
\hline$X_{i k}(f)$ & $\begin{array}{l}\mathrm{k}^{\text {th }} \text { FFT data block for } \mathrm{i}^{\text {th }} \\
\text { microphone, see eqn. (3a) }\end{array}$ \\
\hline$\vec{x}_{m}$ & $\begin{array}{l}\text { distance vector from steering } \\
\text { location to } \mathrm{m}^{\text {th }} \text { microphone, } \mathrm{ft}\end{array}$ \\
\hline$\varepsilon_{R M S}$ & $\begin{array}{l}\text { weighted RMS array response } \\
\text { error }\end{array}$ \\
\hline$\omega$ & $\begin{array}{l}\text { angular frequency }(=2 \pi f) \text {, } \\
\text { radians / second }\end{array}$ \\
\hline
\end{tabular}

\section{$\underline{\text { Introduction }}$}

Aeroacoustic testing capability in both anechoic and hard-walled facilities has grown tremendously over the last several years, with successful collection of noise source location and directivity data in a variety of experiments. One of the reasons for the success of these measurements has been the development of both microphone directional array (DA) instrumentation and associated robust data processing algorithms applied in the analysis of the acquired data. ${ }^{1-7}$ While the gain in test productivity resulting from the use of DA systems has been significant, several challenges remain to be overcome before fully realizing the potential of this technology. For instance, the next generation of array processing algorithms being developed will potentially require the acquisition of significantly more acoustic information than is presently done, in some cases requiring acquisition of acoustic boundary conditions over the entire sphere of source directivity. DA systems involved in these types of tests will employ hundreds or thousands of individual microphones. Traditional array hardware, typically composed of externallybiased condenser microphone / preamplifier / power supply combinations for a number of acquisition channels, is in many instances too expensive to implement a high-density microphone system. Therefore, it is desirable to identify devices and hardware which can be used to implement a system exhibiting measurement performance comparable to the current generation of arrays, but at much lower cost. Several alternate microphone devices have been described in the literature which exhibit characteristics suitable for DA use and at economical cost. Among these are MEMSbased devices described by Sheplak ${ }^{8}$, Saini ${ }^{9}$, and Arnold $^{10}$, and thin-film electret devices described by Hsieh et.al. ${ }^{11}$

Over the last few years, the rapid pace of micro-fabrication technology development has yielded several promising new commercial microphones. Given the increasing interest at Langley Research Center and elsewhere in building higher density array systems, the authors initiated a systematic search for a suitable low-cost commercial off-the-shelf (COTS) microphone which could be used for this purpose. After examining several types of microphones currently available (including externally biased condenser, MEMS, and electret condenser devices), the authors chose to conduct a detailed performance analysis of a prototype DA system populated with COTS Electret Condenser Microphones (ECM's). The objectives of the performance analysis were threefold:

1. Characterize the acoustic response of a suitable ECM via laboratory testing and calibration,

2. Evaluate the beamforming capability of an ECM-based directional array using a series of independently controlled point sources in an anechoic environment, and

3. Demonstrate the utility of an ECM-based directional array in a real-world application. The authors chose as a demonstration to 
apply the ECM array to measurement of source strength and directivity in a cold flow jet at high subsonic and low supersonic velocities.

Note that the cost and performance of the sensors chosen to implement high-density DA systems are critical parameters determining the viability of such arrays, but they are not the only parameters to consider when designing such systems. Microphone package size, data handling efficiency (i.e., efficiency of the data acquisition system), and array mobility (i.e., number and size of cables, power connections, array mounting hardware, etc.) also determine the ultimate success of the system. While microphone package size and construction are discussed subsequently, array data handling and mobility are beyond the scope of this paper reference 10 provides a more detailed discussion of these issues. Rather, it is the purpose of this paper to present an overview of the performance analysis conducted on the prototype ECM-based array constructed for this study. The authors believe this DA system represents a "small scale" version of what can be achieved using economical microphones.

\section{Microphone Construction}

The ECM's employed for this work were "hybrid" devices composed of COTS microphone cartridges coupled with passive signal conditioning circuitry and packaged to enable easy integration into a DA system. The details of the packaging are described below.

ECM Cartridge: Several commercially-available ECM's were investigated for use in construction of the prototype array system. After considering candidate devices, the authors chose to use Panasonic WM-60A ECM cartridges as the sensing element. ${ }^{*}$ Figure 1a illustrates the construction of the ECM cartridge, which houses a recessed 0.25 -inch diaphragm protected by a cap containing a central access hole approximately 0.13 inches in diameter. The microphone incorporates a field-effect transistor

\footnotetext{
* Specific manufacturer's names are explicitly mentioned only to accurately describe the research performed. The use of manufacturer's names does not imply an endorsement by the U.S. Government nor does it imply that the specified equipment is the best available.
}

driver on the output stage and can operate at a maximum supply voltage of $+10 \mathrm{~V}$, with a maximum current draw of $0.5 \mathrm{~mA}$. The nominal sensitivity of a raw WM-60A cartridge when driven by a $+5 \mathrm{~V}$ source through an $8.2 \mathrm{k} \Omega$ load resistor is $15 \mathrm{mV} / \mathrm{Pa}$. Figure $1 \mathrm{~b}$ illustrates the typical response of the microphones, which are designed to exhibit a flat magnitude response over the audio frequency range of $20 \mathrm{~Hz}-20$ $\mathrm{kHz}$.

Equalizing Circuit / Packaging: While a typical WM-60A cartridge operates with a flat response over the audio frequency range, its use in aeroacoustic testing requires that the bandwidth of the device be extended to a significantly higher value. Above $20 \mathrm{kHz}$ the microphone exhibits a first order sensitivity roll-off of approximately $6 \mathrm{~dB}$ per octave relative to its audio range sensitivity. To compensate for this roll-off, the authors designed a passive circuit to equalize the broadband frequency response of the microphone, in essence trading sensitivity for bandwidth. Figure 2 shows a schematic of the ECM cartridge with the equalizing circuit. The circuit was fabricated using surface mount devices on a small printed circuit board and mounted along with the ECM cartridge in a 0.32 -inch outside diameter aluminum cylinder approximately 2 inches in length. An 84-inch, four-conductor cable was attached to the rear of the cylinder via a gold-plated screw connector. The other end of the cable terminated in a quick disconnect coupler which was attached to a power and signal distribution patch panel. A total of 38 microphones were fabricated in this fashion, at an average cost per microphone of approximately $\$ 40$. Figure 3 shows a representative finished microphone.

\section{$\underline{\text { ECM Calibration }}$}

Four different types of calibration data were obtained - the $250-\mathrm{Hz}$ sensitivity of each packaged microphone (raw cartridge coupled with equalizer), the broadband frequency response (magnitude and phase) of each packaged microphone, the background noise level for a sample of raw ECM cartridges, and the total harmonic distortion for a sample of raw cartridges. The various calibration procedures and representative data obtain from them are described subsequently.

Sensitivity: Figure 4 shows a histogram of the 250-Hz sensitivity distribution for the ensemble of 38 packaged microphones used in this study. 
The sensitivity of each microphone was determined using a calibrated pistonphone generating a regulated Sound Pressure Level (SPL) of $94 \mathrm{~dB}$ (relative to a reference pressure of $20 \mu \mathrm{Pa}$ ). The sensitivity of an individual microphone is defined here as the calibration value (specified in units of $\mathrm{mV} / \mathrm{Pa}$ ) which when applied to the output of the excited microphone allows it to indicate an SPL of exactly $94 \mathrm{~dB}$ at $250 \mathrm{~Hz}$. As can be seen in Figure 4, the sensitivities show a partial bimodal distribution centered around 6.25 and $7.75 \mathrm{mV} / \mathrm{Pa}$, with a $6.5 \mathrm{mV} / \mathrm{Pa}$ average sensitivity exhibited for the entire ensemble of microphones. The decrease in the sensitivity of the packaged microphones versus the raw WM-60A cartridges is due to the introduction of the equalizing circuitry. Note that the ensemble distribution is dominated by variations in the sensitivities of individual raw ECM cartridges only. Given the low-cost of these cartridges, if one desires a matched response among the microphones incorporated into a DA system, it is a simple matter to measure the sensitivities of a large sample of cartridges and then choose those with similar characteristics. However, this step was not performed for this study. Rather, the individual measured sensitivities of the packaged microphones were accounted for during analysis of all collected data.

Broadband Frequency Response - Audio Spectrum: The broadband pressure response of each packaged microphone covering the audio frequency spectrum $(250 \mathrm{~Hz}$ to $16000 \mathrm{~Hz})$ was obtained using a standards-traceable Bruel and Kjaer 4226 multifunction calibrator which had been modified to allow access to the transducer driving signal. A special nylon coupler was fabricated to allow insertion of the microphones into the calibrator with minimal acoustic loss. The calibrator generated a constant SPL of $94 \mathrm{~dB}$ and was driven by an external precision signal generator operated over the range of $250 \mathrm{~Hz}-$ $16 \mathrm{kHz}$ in $250-\mathrm{Hz}$ steps. The driving signal from the generator and the microphone output signal were recorded by a two-channel, PC-based transient data recorder with a per-channel sampling rate of $100 \mathrm{ksamples} / \mathrm{sec}$. To obtain the magnitude and phase response of each microphone, the transfer function between the driving signal and microphone output were computed using Welch's averaged periodogram method. $^{12}$

Figure 5 shows the pressure responses obtained using the calibrator for 10 representative microphones. The magnitude response of each device is referenced to its baseline $250-\mathrm{Hz}$ sensitivity. As can be seen in the figure, the ensemble of magnitude responses (with one exception) matched to within $\pm 5 \mathrm{~dB}$ at any one particular frequency while the phase responses matched to within \pm 10 degrees at a particular frequency over the range of $250 \mathrm{~Hz}$ through $16 \mathrm{kHz}$. The matching of phases within the range shown in Figure 5 implies that a directional array populated with these microphones should yield accurate beamformed estimates of noise strength without the need for a phase correction. The limits over which array phase matching needs to be performed are discussed at length by Mosher ${ }^{13}$.

Broadband Frequency Response - Ultrasonic Spectrum: Magnitude and phase responses for each microphone for frequencies above the audio spectrum $(16-40 \mathrm{kHz})$ were obtained using a substitution method freefield calibration. This calibration method conformed with the International Electrotechnical Commission (IEC) standard for calibration of microphone equipment. $^{14} \quad$ Each fabricated electret microphone was mounted in an 8 -foot by 12 -foot by 6-foot high anechoic chamber directly in line with a series of 1.0-inch diameter ultrasonic ceramic transducers, as shown in the sketch in Figure 6. Each transducer was positioned 74 inches from the microphone. The shortest microphone to chamber wedge-tip distance was approximately 24 inches. A custom mounting bracket with attached guide bar, shown in Figure 7, allowed correct alignment of each microphone in the chamber such that all diaphragms occupied as closely as possible the same axial location with respect to the source. Freefield calibration data were obtained at frequencies of $23.176,29.976$, and $39.576 \mathrm{kHz}$ by operating each of three different ceramic transducers at its resonant frequency (to eliminate higher-order source diaphragm vibration modes). The transducer driving signal and the microphone output signal were recorded by the same two-channel PC-based transient data recorder used for the audio spectrum calibration, at a per-channel sampling rate of $100 \mathrm{ksamples} / \mathrm{sec}$. Upon completion of acquisition of calibration data using the three ceramic transducers, the electret microphone was replaced with a standards-traceable Bruel and Kjaer 4136 reference microphone and a repeat set of calibration data was acquired using the three transducers. The freefield magnitude and 
phase response of the electret microphone at the resonant frequency of each transducer was obtained using Welch's method in a similar manner to the audio spectrum calibration.

One challenge encountered during the freefield calibration process concerned the determination of the proper corrections to apply to the freefield phase response. Such corrections were required to account for offsets introduced in the line of sight distance between the ceramic transducer and the microphone when installing different devices in the anechoic chamber, since the guide bar on the mounting bracket shown in Figure 7 provided a necessary, but not sufficient alignment. The preferred method for computing the phase correction was to generate a very short duration resonant frequency chirp using the ceramic transducer and then measure the time for the sound wave to travel from the source to each reference or test microphone. Unfortunately, the ceramic transducers employed for the test did not produce a chirp signature suitable for accurately determining the transit time. Thus, an alternate procedure was developed to obtain the phase corrections using a high frequency paper-cone tweeter in place of the ceramic transducers. The tweeter provided a much cleaner chirp signature for determining small transit time variations, and care was taken to not move the tweeter when installing different devices in the mounting fixture. Using an acquisition sampling rate of $300 \mathrm{ksamples} / \mathrm{sec}$, sufficient to resolve $\approx 3 \mu \mathrm{sec}$ time increments, the distance offset for each of the 38 microphones when installed into the anechoic chamber was adequately determined via a time series cross covariance analysis. Note that this process assumed that the reinstallation of a microphone into the mounting bracket using the guide bar resulted in an additional offset of no more than a few thousandths of an inch, corresponding to sub-microsecond travel time adjustments. As will be seen in the phase data shown subsequently, this correction procedure worked very well in practice.

Figure 8 shows the freefield responses for ten representative packaged microphones obtained using the procedure described above. The freefield data (converted to pressure response) is overlaid with the Figure 5 audio spectrum pressure response data. As can be seen in the figure, the ultrasonic magnitude responses were matched to within $\pm 5 \mathrm{~dB}$ at a given frequency while the phase responses were matched to within \pm 25 degrees. Since the high frequency phase response deviation between microphones greatly exceeded \pm 10 degrees, a phase correction was applied when using these devices in a DA system at frequencies above $20 \mathrm{kHz}$. Given that only three freefield calibration frequencies were acquired (due to the limited availability of ceramic transducers at ultrasonic frequencies below $40 \mathrm{kHz}$ ), a linear interpolation procedure was employed to provide the narrowband phase correction at frequencies other than the resonant ceramic ones.

Background Noise Measurement: The background noise level of a raw ECM cartridge was determined using a vacuum-isolation chamber mounted on a vibration-damped table. ${ }^{15}$ The vacuum-isolation chamber consisted of an inner chamber maintained at ambient conditions into which the cartridge was placed. The inner chamber was then suspended within a vacuum chamber to provide a high degree of acoustic isolation from the surrounding environment. Figure 9 illustrates the background noise autospectrum for a typical cartridge for three different vacuum pressures. As can be seen in the figure, classic $1 / f$ noise dominates the response at the lower end of the frequency spectrum. The background noise characteristic exhibited in Figure 9 is typical for electret-type microphones.

Total Harmonic Distortion: The total harmonic distortion (THD) for a series of raw ECM cartridges was determined using an externally driven Whittaker PC-125 acoustic calibrator excited at a frequency of $1 \mathrm{kHz}$ for a range of sound pressure levels spanning $100-140 \mathrm{~dB}$. The THD for a microphone is defined as the root mean square (RMS) value of the total harmonics of a measured calibration signal, divided by the RMS value of the fundamental plus harmonics of the signal. This can be expressed in percentage form as

$$
T H D=\frac{P_{H}}{P_{F}} \times 100 \%
$$

where $P_{H}$ and $P_{F}$ are defined as

$$
\begin{gathered}
P_{H}=\sqrt{P_{2}^{2}+P_{3}^{2}+\cdots+P_{n}^{2}} \\
P_{F}=\sqrt{P_{1}^{2}+P_{2}^{2}+P_{3}^{2}+\cdots+P_{n}^{2}}
\end{gathered}
$$


measured over the first $\mathrm{n}$ harmonics. It was determined empirically that the fundamental and first three harmonics were sufficient to obtain an accurate estimate of the THD for the ECM cartridges tested.

Figure 10 shows the THD measured on ten representative cartridges. Indicated on the plot is the average SPL level at which the THD reaches four percent. Sound pressure levels encountered during aeroacoustic testing in ground facilities (anechoic chambers, treated wind tunnels, etc.) typically do not exceed $120 \mathrm{~dB}$; therefore, the maximum expected THD when using these microphones in a DA application is approximately $1-2 \%$.

\section{Directional Array Evaluation System}

Array Construction: The performance analysis objective of testing the packaged electret microphones in a prototype DA was facilitated by utilizing an existing array mounting system. For this purpose, the authors chose to utilize the Langley Large Aperture Directional Array (LADA). ${ }^{16}$ A photograph of the LADA is shown in Figure 11. A four-foot diameter fiberglass panel provided a flat surface to flush mount all microphones. The panel was attached to a pantilt unit secured to a rigid tripod support. This allowed precise alignment changes in the elevation and azimuth of the face of the array. A small laser diode pointer was place at $\vec{x}_{c}$, corresponding to the phase center of the array (in this case the center of the fiber glass panel), to aid in array alignment. The LADA incorporated 35, 0.32-inch diameter microphone mounting holes arranged in a two-dimensional pattern consisting of logarithmic spirals. This microphone layout, shown in Figure 12, was based on a design by Underbrink et.al. at Boeing (see chapter 3 in reference 7). It consisted of five spirals of seven microphones each with the inner-most microphones lying on a 1 -inch radius and the outer-most on a 17 -inch radius. This design resulted in acceptable beamwidth and minimal sidelobe height over an operational frequency range of $2-30 \mathrm{kHz}$. The microphone mounting coordinates, referenced to $\vec{x}_{c}$, are listed in Table I.

Array Population: The LADA was populated with either of two types of sensors (1) commercial, standards-traceable, 0.25-inch externally-biased Bruel and Kjaer 4136 condenser microphones (hereafter referred to as the "reference LADA"), and (2) fabricated and packaged electret microphones (hereafter referred to as the "ECM LADA"). The reference LADA microphones were powered by a bank of regulated DC supplies, one for each microphone. The ECM LADA was powered by a single regulated DC power supply, since the current draw from each electret microphone was no more than $0.3 \mathrm{~mA}$ using a supply voltage of $+5 \mathrm{~V}$ and a load resistor of $8.2 \mathrm{k} \Omega$. In all cases the output signals from each microphone were conditioned using high-pass elliptic filters at a frequency of $300 \mathrm{~Hz}$. Although not required, the electret microphone outputs were additionally amplified by a factor of 10 after filtering.

Data Acquisition: The data acquisition system consisted of a 64-channel transient data recorder controlled by a PC. All data channels were simultaneously recorded with a 16-bit dynamic range at a sampling rate of $100 \mathrm{kHz}$. The analog bandwidth of the system at this sampling rate was $40 \mathrm{kHz}$ based on the settings of the anti-aliasing filters. Typical acquisition run times ranged from 5 to 10 seconds with the data stored in raw binary format on the PC hard drive.

Data Reduction: Post processing of acquired LADA data began with the computation of an $M x M$ cross-spectral matrix for each ensemble of data, where $M$ is the total number of microphones in the array. The computation of the individual matrix elements was performed using Fast Fourier Transforms (FFT) of the original data ensemble. This was done after converting the raw data to engineering units. The time data were segmented into a series of nonoverlapping blocks each containing 4096 samples. Using a Hamming window, each of these blocks of data was Fourier transformed into the frequency domain with a frequency resolution of 24.4 Hz. The individual cross spectrum for microphones $i$ and $j$ was computed via

$$
G_{i j}(f)=\frac{1}{N W_{s}} \sum_{k=1}^{N}\left[X_{i k}^{*}(f) X_{j k}(f)\right]
$$

where $W_{S}$ is the Hamming window weighting constant, $N$ is the number of blocks of data, and $X$ is an FFT data block. The full matrix was formed as 


$$
\hat{G}=\left[\begin{array}{cccc}
G_{11} & G_{12} & \cdots & G_{1 M} \\
& G_{22} & & \vdots \\
& & \ddots & \vdots \\
& & & G_{M M}
\end{array}\right] .
$$

The lower triangular elements of this Hermitian matrix were computed by taking the complex conjugates of the upper triangular elements. All cross spectral matrix elements were employed in subsequent processing, with no modification of the diagonal terms. Note that for in-flow applications of the array, the diagonal terms can be removed to improve the spectral dynamic range by subtracting off self-noise dominated auto-spectra during the beamforming process (see chapter 1 of reference 7). However, this additional step was not required for the data acquired as part of this study.

A classical delay and sum beamforming approach was used for the analysis of the array data. This approach assumed distributions of monopoles for the measured sources. In delay and sum beamforming, the array is electronically "steered" to a series of chosen source locations. For each selected steering location, a steering vector $\hat{e}$ containing a retarded time phase adjustment for each microphone in the array was defined as

$$
\hat{e}=\left[\begin{array}{c}
\frac{r_{1}}{r_{c}} \exp \left[j\left(\vec{k} \cdot \vec{x}_{1}\right)\right] \\
\vdots \\
\frac{r_{m}}{r_{c}} \exp \left[j\left(\vec{k} \cdot \vec{x}_{m}\right)\right]
\end{array}\right]
$$

where $\vec{k}$ is the acoustic wave vector, $\vec{x}_{m}$ is the distance vector from the steering location to each microphone $m, \omega$ is the angular frequency, and the ratio $\left(r_{m} / r_{c}\right)$ is included to normalize the distance related amplitude to that of the phase center of the array. The output power spectrum (or response) of the LADA at the steering location was obtained from

$$
P(\hat{e})=\frac{\hat{e}^{T} \hat{G} \hat{e}}{M^{2}}
$$

where the superscript $T$ denotes a complex transpose of the matrix, and $P(\hat{e})$ is a meansquared-pressure quantity. The division by $\mathrm{M}^{2}$ serves to reference the array output level to an equivalent single microphone output level. References (16) and (17) provide greater detail concerning additional processing performed on the LADA data.

\section{ECM LADA Evaluation}

Test Configuration: The beamforming capability of the ECM LADA was evaluated in the Langley Anechoic Noise Research Facility (ANRF). The ANRF is an anechoic chamber measuring $27.5 \mathrm{ft}$ x $27.5 \mathrm{ft} \times 25.6 \mathrm{ft}$ in which static or wind tunnel testing can be performed. The facility is primarily employed for engine nacelle noise studies. To assess the capability of the ECM LADA to identify discrete incoherent noise sources, independently controlled speakers were installed in the facility. These speakers were attached to mounting platforms positioned at various locations with respect to the center of the array. Figure 13 illustrates one such configuration where a single source (consisting of a piezo-electric cone tweeter) was located 8 feet directly in front of the array. Both pure tone and white noise signals were recorded by the array microphones and processed using the data analysis procedures described previously. All calibrations performed on the ECM LADA were repeated for the reference LADA, using the same calibration frequencies, source strengths, and source locations.

Performance Metrics: Two quantitative metrics were used to assess the accuracy of the beamformed output when using the ECM LADA to characterize point sources in the ANRF. The first metric consisted of computation of a weighted RMS error for the beamformed output of the ECM LADA compared with similar output from the reference LADA. Using an expression similar to that presented by Arnold, et.al. ${ }^{18}$, the weighted RMS error summed over all steering locations measured by the array can be expressed as

$$
\varepsilon_{R M S}=\sqrt{\frac{\sum_{k=1}^{K} T_{k}\left(R_{k}-T_{k}\right)^{2}}{K}}
$$


where $T_{k}$ is the normalized measured response by the ECM LADA, $R_{k}$ is the normalized measured response by the reference LADA, and $K$ is the total number of measured steering locations.

The second performance metric consisted of comparing the beamformed output of the ECM LADA with its theoretical response. Assuming a simple monopole source, the LADA ideal array response can be expressed as

$$
W\left(k, \vec{x}, \vec{x}^{o}\right) \equiv \sum_{m=1}^{M} \frac{r^{o}}{r_{m}^{o}} e^{j k\left[\left(r^{o}-r\right)-\left(r_{m}^{o}-r_{m}\right)\right]}
$$

where $\vec{x}$ is an arbitrary Cartesian location in space to which the array is electronically steered, $\vec{x}^{o}$ is the source location, $r^{o}$ and $r_{m}{ }^{o}$ are the distances from the source to $\vec{x}_{c}$ and the $\mathrm{m}^{\text {th }}$ microphone, respectively, and $r$ and $r_{m}$ are the distances from the steering location to $\vec{x}_{c}$ and the microphone, respectively. The response shown in eqn. (7) is normally expressed in decibels referenced to the level obtained at $\vec{x}^{o}$ :

$$
d B(\vec{x})=20 \log _{10}\left[\frac{\left|W\left(k, \vec{x}, \vec{x}^{o}\right)\right|}{\left|W\left(k, \vec{x}^{o}, \vec{x}^{o}\right)\right|}\right]
$$

Eqn. (8) is plotted as a color contour map with contour level proportional to $d B(\vec{x})$, computed over the complete ensemble of measured steering locations. Color contour maps generated using eqn. (8) over a range of beamform frequencies were compared with their experimental counterparts to assess the response fidelity of the ECM LADA.

Sample Results: Figure 14 illustrates the theoretical and experimental array responses for the ECM and reference LADA's measuring the $5-\mathrm{kHz}$ narrowband component of a generated white noise source. The tweeter source (shown in Figure 13), was located with respect to the center of the LADA at $(0.0,0.0,96.0)$ inches. The theoretical response was computed using eqns. (7) and (8), while the experimental beamformed output of the LADA was obtained using eqn. (5). Figures 15 and 16 illustrate similar responses for the $10-\mathrm{kHz}$ and $20-\mathrm{kHz}$ narrowband component of the white noise spectrum, respectively. As can be seen in these figures, the spatial distribution of sidelobes is very similar between the theoretical response, ECM LADA output, and reference LADA output. The lower right portion of each figure shows a horizontal slice through each contour plot (normalized to the reference LADA output) and further illustrates the uniformity of the sidelobe structure when comparing the two arrays.

Table II lists the weighted RMS errors for frequencies spanning the range of $315 \mathrm{~Hz}$ - $20 \mathrm{kHz}$, computed using eqn. (6) for normalized ECM- and reference-LADA beamform outputs similar to those shown in Figures 14 - 16. The error values are plotted in Figure 17. It is clearly seen in this figure that the weighted RMS errors are higher for very low beamform frequencies, but approach a frequency-invariant average value of 0.0046 above $2500 \mathrm{~Hz}$. This is a remarkable result and indicates that for the data obtained using a single point source in the ANRF, the beamform results when using the reference and ECM LADA's are extremely consistent above a frequency of $2500 \mathrm{~Hz}$. Interestingly, this frequency also corresponds closely with the theoretical low frequency limit of the array microphone pattern for the LADA.

\section{Cold Flow Jet ECM LADA Demonstration}

Along with the beamforming evaluation using distributions of point sources, it was also desired to demonstrate the utility of the ECM LADA in a real-world application. The authors chose as a demonstration to apply the array in a series of simple measurements of source strength and directivity in a cold flow jet operated at high subsonic exit velocities in the ANRF. Note that it is beyond the scope of this paper to present a detailed study of jet noise using the array. Rather, the goal of the demonstration was to apply and evaluate the ECM LADA in a rich sound field containing broadband noise and high background levels.

The jet which was chosen for the demonstration was a 2-inch diameter, Mach 1.0 contour convergent nozzle which had been previously used for measurements of mean pressure and farfield acoustics. ${ }^{19}$ Figure 18 shows a photo of the nozzle mounted in the ANRF with the ECM LADA shown in the background. The majority of the nozzle shown in the photo was covered with acoustic foam to prevent sound reflections. The jet was operated at high subsonic exit velocities spanning Mach 
numbers from 0.50 to 0.99 to provide generated noise which was then measured by the array. Noise data were acquired at several orientations of the array with respect to the jet exit plane (i.e., various azimuth angles with respect to the jet axis) to obtain a measure of the jet directivity. Figure 19 shows a sample noise location map for a narrowband frequency of $5 \mathrm{kHz}$ obtained with the LADA positioned 8 feet from the center of the nozzle, pointing directly at the exit plane (azimuth angle $=90$ degrees).

One useful characteristic of a DA system when measuring free jet flow noise is the array's ability to extract from the beamformed data the variation of the axial location of the jet peak source strength as a function of frequency. As discussed by Lilley ${ }^{20}$, the axial location data should collapse to single curve when the frequency parameter is expressed as the Strouhal number

$$
S t=\frac{f D_{j}}{U_{j}}
$$

where $f$ is the acoustic frequency, $D_{j}$ is the jet diameter, and $U_{j}$ is the jet exit velocity. Figure 20 shows the axial location of the jet peak source strength as measured by the ECM LADA for three different jet exit velocities spanning Mach numbers from 0.5 to 0.99 . Also shown in the figure are two theoretical curves presented by Lilley in reference 20 which were obtained from calculations based on Lighthill's acoustic analogy. The lower curve is based on the assumption of a zero initial thickness for the jet mixing region. The upper curve is based on the assumption that the mixing region becomes fully turbulent a defined distance downstream from the jet exit. These two curves bracket the ECM LADA results, indicating a good ability of the array to extract useful information from the jet noise data.

\section{Summary}

Directional array technology will continue to be an integral part of experimental aeroacoustics. However, cost remains a limiting factor in the construction of future high-density array systems which will be needed to implement advanced beamforming algorithms. In an effort to reduce the construction costs of future arrays, the authors have undertaken a systematic investigation of one class of economical sensing device, the electret condenser microphone. A series of customized microphones based on the
Panasonic WM-60A electret cartridge were fabricated for use with the Langley Large Aperture Directional Array. The results of the investigation revealed a fabricated microphone frequency response suitable for directional array use, with minimal magnitude and phase response variations in the audio frequency spectrum and moderate variations at higher frequencies. Also, the results using an ECM-populated LADA to measure point source noise in the Langley ANRF revealed excellent agreement between reference array data, theoretical array response, and the LADA beamformed output. Finally, a successful demonstration was conducted using the ECM LADA to measure properties of the noise field generated by a cold flow jet. Thus, economical COTS electret microphones show great promise for array work, especially for lower-frequency applications such as the jet noise demonstration presented here. Additional studies similar to this one are planned for COTS MEMS microphones which have recently become available.

\section{Acknowledgments}

The authors gratefully acknowledge the contributions of Mick Hartzheim of the Raytheon Company in the construction of the packaged electret microphones, and of Beverly Anderson of the NASA Langley Aeroacoustics and Hypersonics Propulsion Support Section in the construction, installation, and operation of the cold flow jet.

\section{$\underline{\text { References }}$}

1. Gramann, R.A., and Mocio, J.W., "Aeroacoustic Measurements in Wind Tunnels Using Adaptive Beamforming Methods”, Journal of the Acoustical Society of America, Vol. 97, Number 6, pp. 694$701,1995$.

2. Watts, M.E., Mosher, M., and Barnes, M.J., "The Microphone Array Phased Processing System (MAPPS)", AIAA Paper 96-1714, $2^{\text {nd }}$ AIAA/CEAS Aeroacoustics Conference, State College, PA, 1996.

3. Meadows, K.R., Brooks, T.F., Humphreys, W.M., Jr., Hunter, W.W., Jr., and Gerhold, C.H., "Aeroacoustic Measurements of a Wing-Flap Configuration", AIAA Paper 97$1595,3^{\text {rd }}$ AIAA/CEAS Aeroacoustics Conference, Atlanta, GA, 1997. 
4. Dougherty, R.P., and Stoker, R.W., "Sidelobe Suppression for Phased Array Aeroacoustic Measurements", AIAA Paper $98-2242,4^{\text {th }}$ AIAA/CEAS Aeroacoustics Conference, Toulouse, France, 1998.

5. Storms, B.L., Ross, J.C., Horne, W.C., Hayes, J.A., Dougherty, R.P., Underbrink, J.R., Scharpf, D.F., and Moriarty, P.J., "An Aeroacoustic Study of an Unswept Wing with a Three-Dimensional High-Lift System", NASA TM-1998-112222, 1998.

6. Brandstein, M., and Ward, D. (ed.), Microphone Arrays - Signal Processing Techniques and Applications, SpringerVerlag, Berlin, Germany, 2001.

7. Mueller, T.J. (ed.), Aeroacoustic Measurements, Springer-Verlag, Berlin, Germany, 2002.

8. Sheplak, M., Breuer, K.S., and Schmidt, M.A., "A Wafer-Bonded, Silicon-Nitride Membrane Microphone with DielectricallyIsolated Single Crystal Silicon Piezoresistors", Proceedings of the SolidState Sensor and Actuator Workshop, pp. 23-26, 1998.

9. Saini, R., Bhardwaj, S. , Nishida, T., and Sheplak, M., "Scaling Relations for Piezoresistive Microphones", Proceedings of the ASME IMECE 2000, Orlando, Florida, 2000.

10. Arnold, D.P., "A MEMS-Based Directional Acoustic Array for Aeroacoustic Measurements", Master's Thesis, University of Florida, Gainesville, Florida, 2001.

11. Hsieh, W.H., Yao, T.J., and Tai, Y.C., "A High Performance MEMS Thin-film Teflon Electret Microphone", 1999 International Conference on Solid-State Sensors and Actuators (Transducer '99), Sendai, Japan, 1999.

12. Welch, P.D., "The Use of Fast Fourier Transform for the Estimation of Power Spectra: A Method Based on Time Averaging Over Short, Modified Periodograms", IEEE Transactions on Audio
Electroacoustics, Vol. AU-15, pp. 70-73, 1967.

13. Mosher, M., Watts, M.E., Jaeger, S.M., and Jovic, S., "Calibration of Microphone Arrays for Phased Array Processing", AIAA Paper $\quad 97-1678, \quad 3^{\text {rd }}$ AIAA/CEAS Aeroacoustics Conference, Atlanta, GA, 1997.

14. International Electrotechnical Commission (IEC), Standard 60268-4, "Sound System Equipment - Part 4: Microphones”, 1997.

15. Ngo, K.C.T., and Zuckerwar, A.J., "Acoustic Isolation Vessel for Measurement of the Background Noise in Microphones", Journal of the Acoustical Society of America, Vol. 93, Number 5, pp. 2974-2980, 1993.

16. Humphreys, W.M., Jr., Brooks, T.F., Hunter, Jr., W.W., and Meadows, K.R., "Design and Use of Microphone Directional Arrays for Aeroacoustic Measurements", AIAA Paper 98-0471, 36 ${ }^{\text {st }}$ Aerospace Sciences Meeting and Exhibit, Reno, NV, 1998.

17. Brooks, T.F., and Humphreys, W.M., Jr., "Effect of Directional Array Size on the Measurement of Airframe Noise Components", AIAA Paper 99-1958, $5^{\text {th }}$ Aeroacoustics Conference, Seattle, WA, 1999.

18. Arnold, D.P., Nishida, T., Cattafesta, L.N., and Sheplak, M., "MEMS-Based Acoustic Array Technology", AIAA Paper 2002-0253, $40^{\text {th }}$ AIAA Aerospace Sciences Meeting and Exhibit, Reno, NV, 2002.

19. Norum, T.D. and Seiner, J.M, "Measurements of Mean Static Pressure and Far-Field Acoustics of Shock-Containing Supersonic Jets", NASA Technical Memorandum 84521, September, 1982.

20. Lilley, G.M., "Jet Noise Classical Theory and Experiments", published in "Aeroacoustics of Flight Vehicles: Theory and Practice", NASA Reference Publication 1258, Volume 1, pp. 211-289, 1991. 
Table I - LADA Microphone Coordinates (Viewed from Front of Array)

\begin{tabular}{|c|c|c|c|c|c|c|c|}
\hline Mic \# & $\begin{array}{c}\text { X } \\
\text { location }\end{array}$ & $\begin{array}{c}\text { Y } \\
\text { location }\end{array}$ & $\begin{array}{c}\text { Z } \\
\text { location }\end{array}$ & Mic \# & $\begin{array}{c}\text { X } \\
\text { location }\end{array}$ & $\begin{array}{c}\text { Y } \\
\text { location }\end{array}$ & $\begin{array}{c}\text { Z } \\
\text { location }\end{array}$ \\
\hline & (in) & (in) & (in) & & (in) & (in) & (in) \\
\hline 1 & 0.03 & -1.02 & 0.00 & 19 & -9.99 & 5.66 & 0.00 \\
\hline 2 & 0.97 & -0.32 & 0.00 & 20 & -8.47 & -7.78 & 0.00 \\
\hline 3 & 0.61 & 0.80 & 0.00 & 21 & 10.57 & -8.60 & 0.00 \\
\hline 4 & -0.57 & 0.81 & 0.00 & 22 & 11.44 & 7.37 & 0.00 \\
\hline 5 & -0.93 & -0.30 & 0.00 & 23 & -3.47 & 13.14 & 0.00 \\
\hline 6 & -5.13 & 0.88 & 0.00 & 24 & -13.56 & 0.75 & 0.00 \\
\hline 7 & -2.42 & -4.63 & 0.00 & 25 & -4.89 & -12.69 & 0.00 \\
\hline 8 & 3.67 & -3.75 & 0.00 & 26 & 14.55 & -5.15 & 0.00 \\
\hline 9 & 4.71 & 2.30 & 0.00 & 27 & 9.39 & 12.22 & 0.00 \\
\hline 10 & -0.73 & 5.17 & 0.00 & 28 & -8.73 & 12.68 & 0.00 \\
\hline 11 & -2.34 & -8.63 & 0.00 & 29 & -14.74 & -4.38 & 0.00 \\
\hline 12 & 7.50 & -4.91 & 0.00 & 30 & -0.39 & -15.42 & 0.00 \\
\hline 13 & 6.99 & 5.59 & 0.00 & 31 & 17.01 & -1.12 & 0.00 \\
\hline 14 & -3.16 & 8.35 & 0.00 & 32 & 6.32 & 15.81 & 0.00 \\
\hline 15 & -8.92 & -0.42 & 0.00 & 33 & -13.08 & 10.89 & 0.00 \\
\hline 16 & 4.80 & -10.49 & 0.00 & 34 & -14.39 & -9.09 & 0.00 \\
\hline 17 & 11.45 & 1.30 & 0.00 & 35 & 4.21 & -16.52 & 0.00 \\
\hline 18 & 2.31 & 11.28 & 0.00 & & & & \\
\hline
\end{tabular}

Table II - RMS Errors for ECM LADA with Tonal Point Source

\begin{tabular}{|c|c|}
\hline Frequency, $\mathrm{Hz}$ & $\varepsilon_{\text {RMS }}$ \\
\hline 315.0 & 0.0591 \\
\hline 400.0 & 0.0288 \\
\hline 500.0 & 0.0409 \\
\hline 630.0 & 0.0294 \\
\hline 800.0 & 0.0279 \\
\hline 1000.0 & 0.0112 \\
\hline 1250.0 & 0.0134 \\
\hline 1600.0 & 0.0146 \\
\hline 2000.0 & 0.0102 \\
\hline 2500.0 & 0.0047 \\
\hline 3150.0 & 0.0041 \\
\hline 4000.0 & 0.0060 \\
\hline 5000.0 & 0.0051 \\
\hline 6300.0 & 0.0040 \\
\hline 8000.0 & 0.0036 \\
\hline 10000.0 & 0.0037 \\
\hline 12500.0 & 0.0038 \\
\hline 16000.0 & 0.0056 \\
\hline 20000.0 & 0.0058 \\
\hline
\end{tabular}




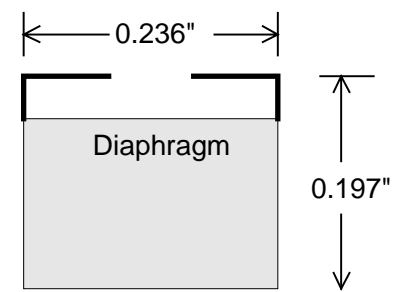

(a)

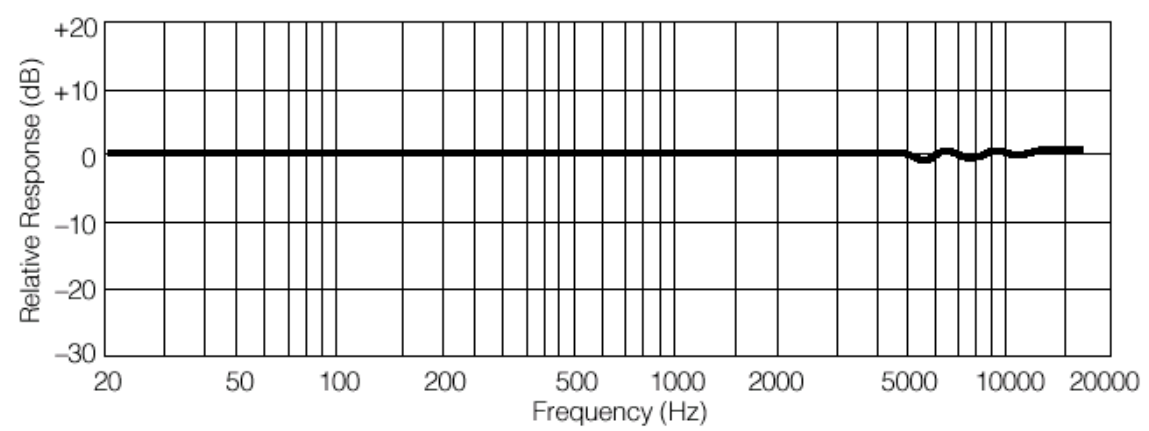

(b)

Figure 1. (a) Internal Construction of Electret Microphone.

(b) Manufacturer's Audio Frequency Response.

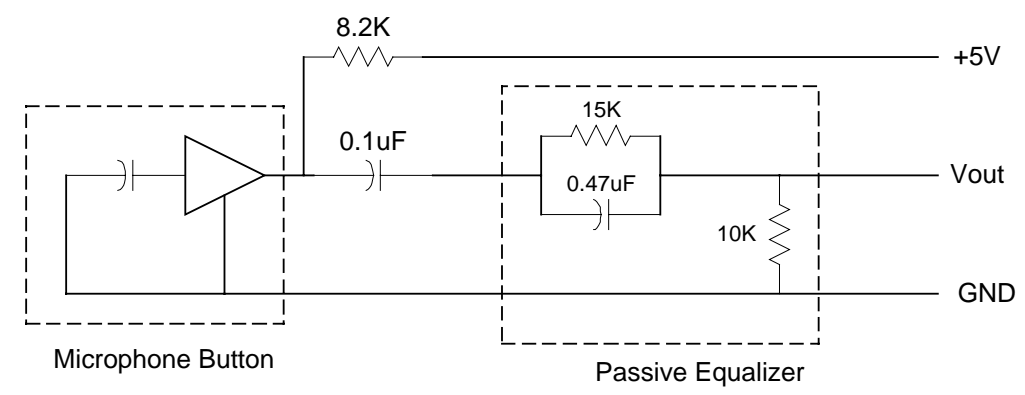

Figure 2. Schematic of Electret Microphone, Power Loading, and Passive Equalizer.

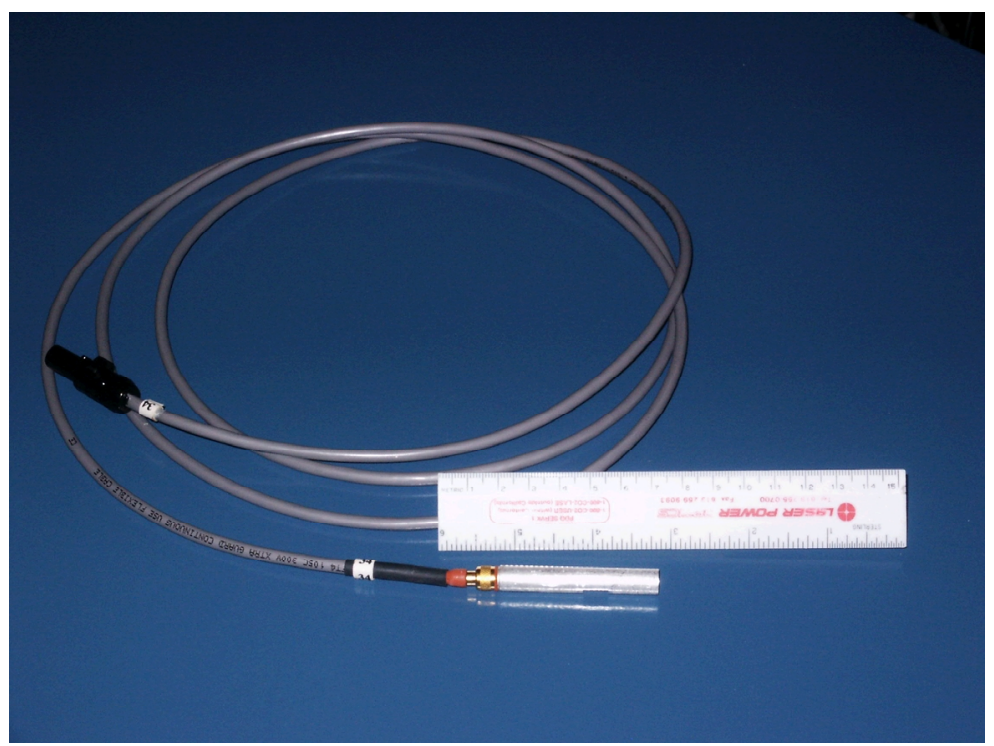

Figure 3. Representative Fabricated Microphone and Cable.

American Institute of Aeronautics and Astronautics 


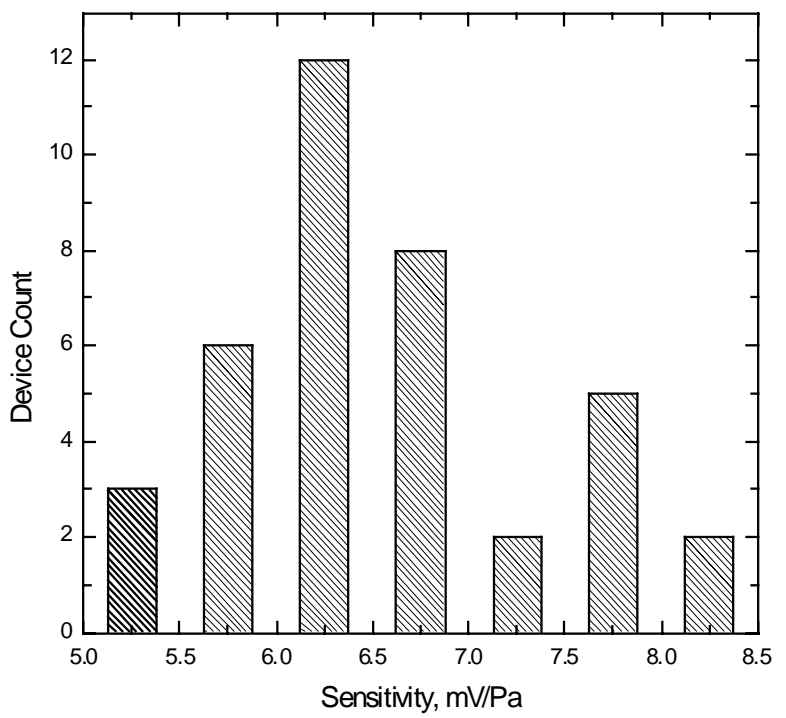

Figure 4. Histogram of Sensitivities for Packaged Microphones.
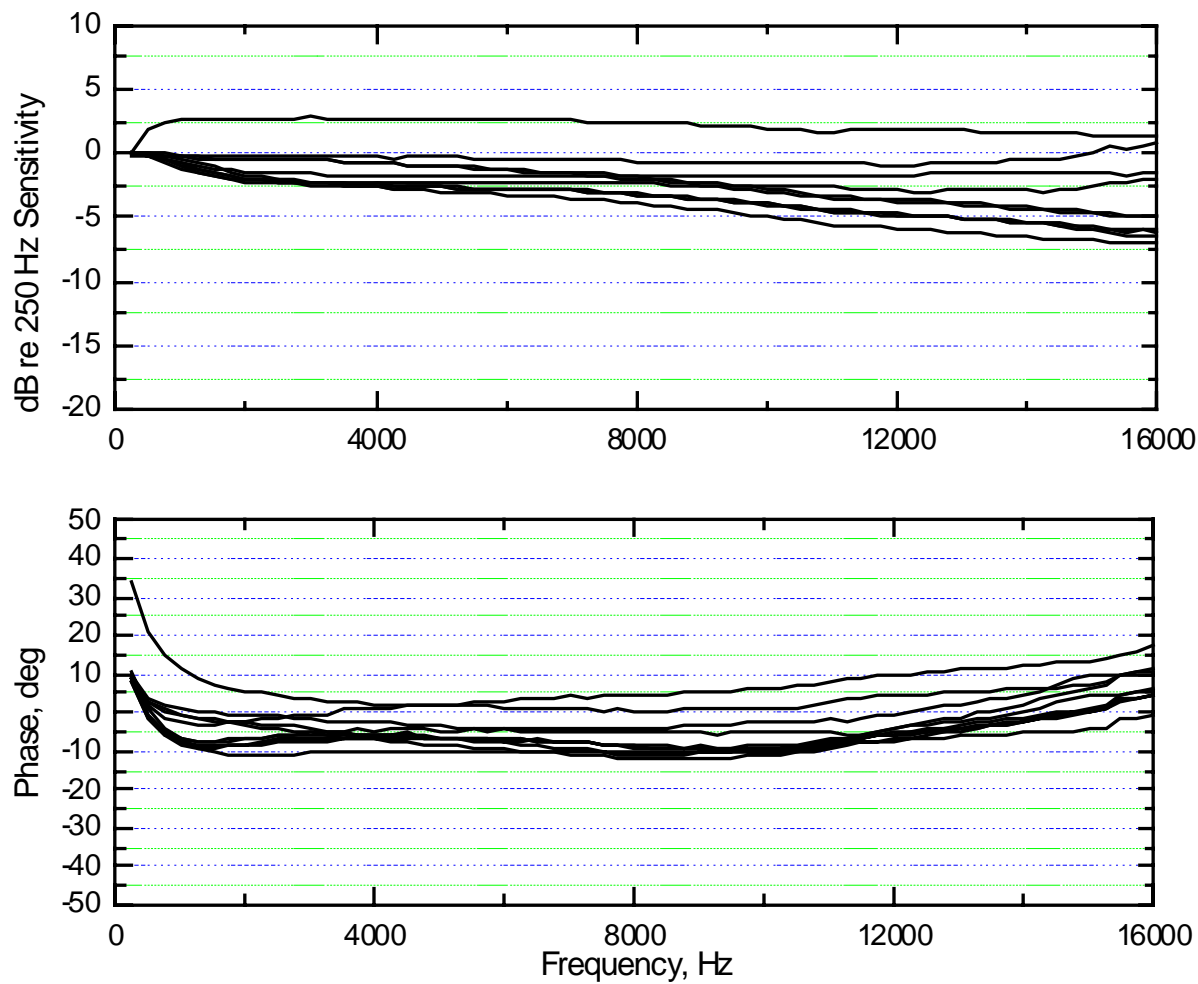

Figure 5. Audio Spectrum Response of 10 Representative Packaged Microphones. Measured Using B\&K 4226 Multifunction Calibrator. 


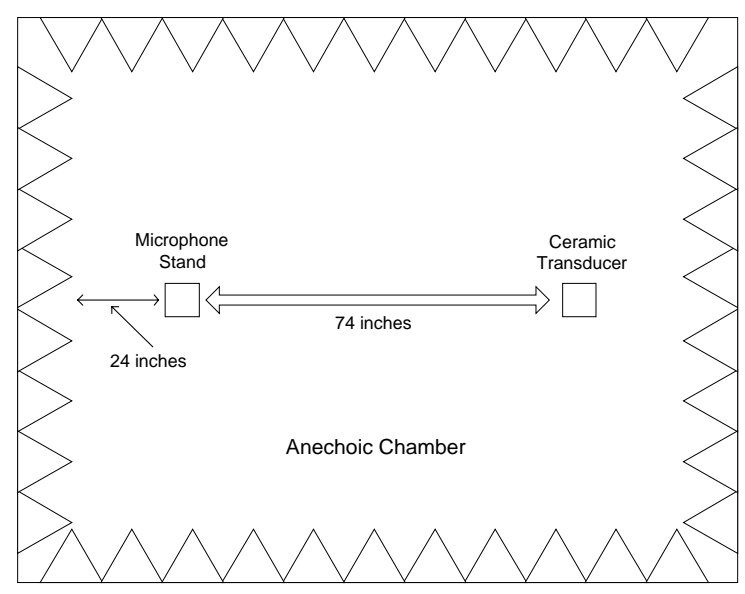

Not to Scale

Figure 6. Sketch of Anechoic Chamber Freefield Calibration Configuration.

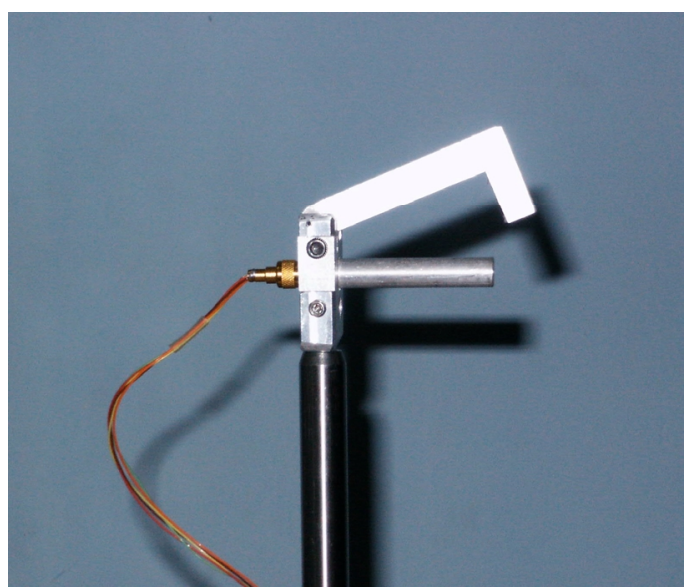

Figure 7. Photo of Freefield Mounting Bracket with Attached Guide Bar
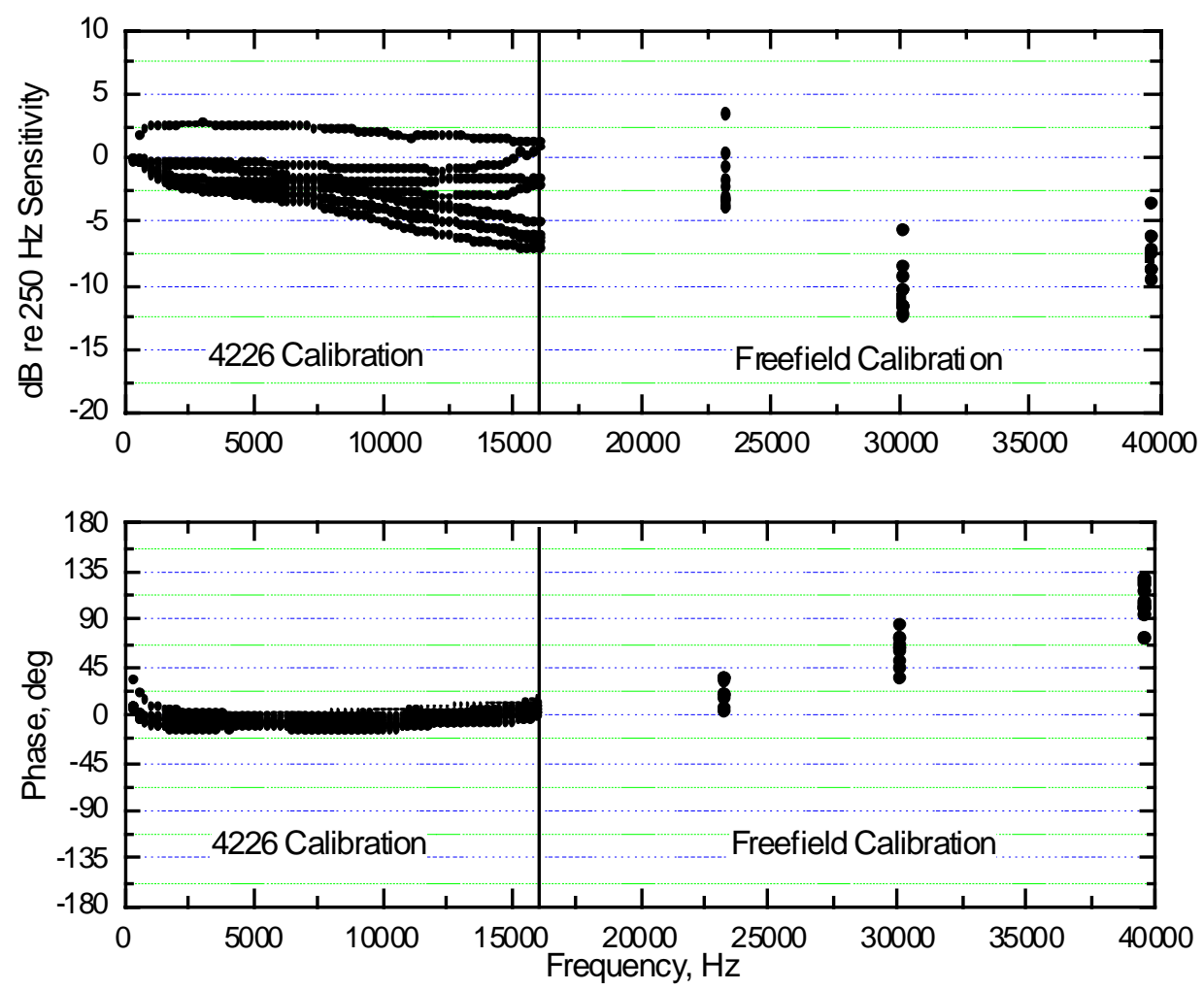

Figure 8. Total Response of 10 Representative Packaged Microphones. Left Side - Audio Spectrum Calibration using B\&K 4226 Calibrator. Right Side - Freefield Ultrasonic Transducer Calibration. 


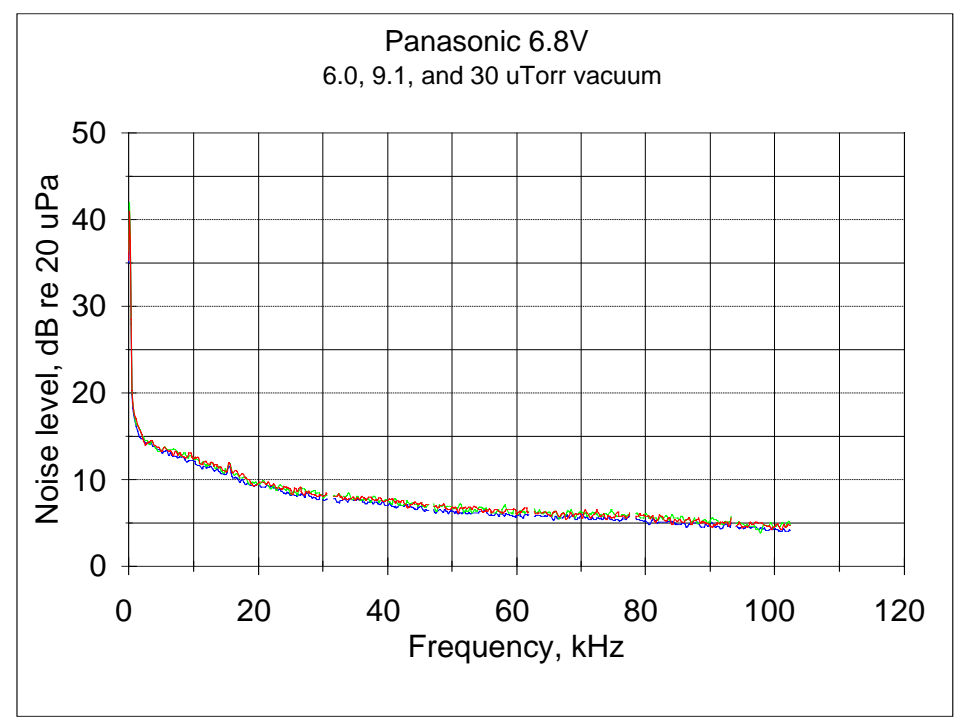

Figure 9. Typical Vacuum-Isolation Chamber Background Spectra for Raw ECM Cartridge.

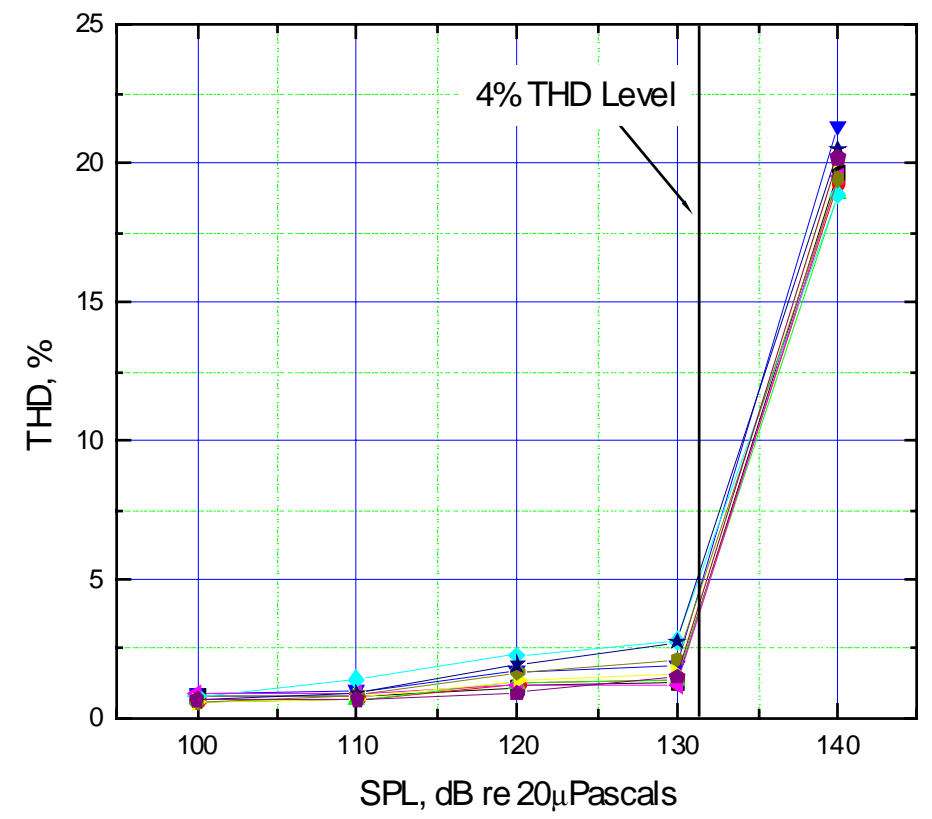

Figure 10. Total Harmonic Distortion of Ensemble of Raw ECM Cartridges. 


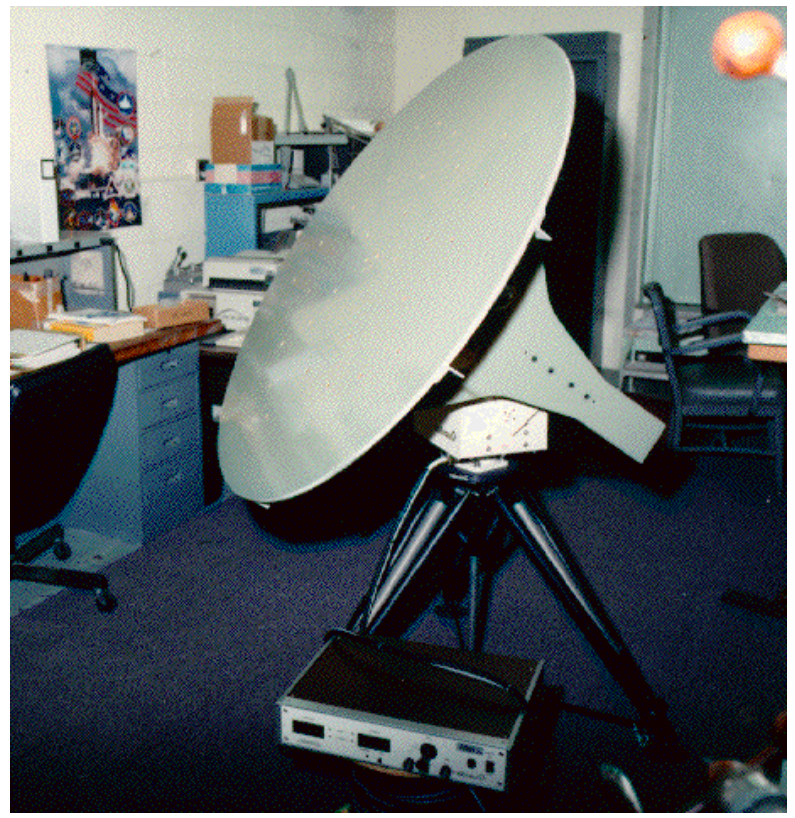

Figure 11. Langley Large Aperture Directional Array.

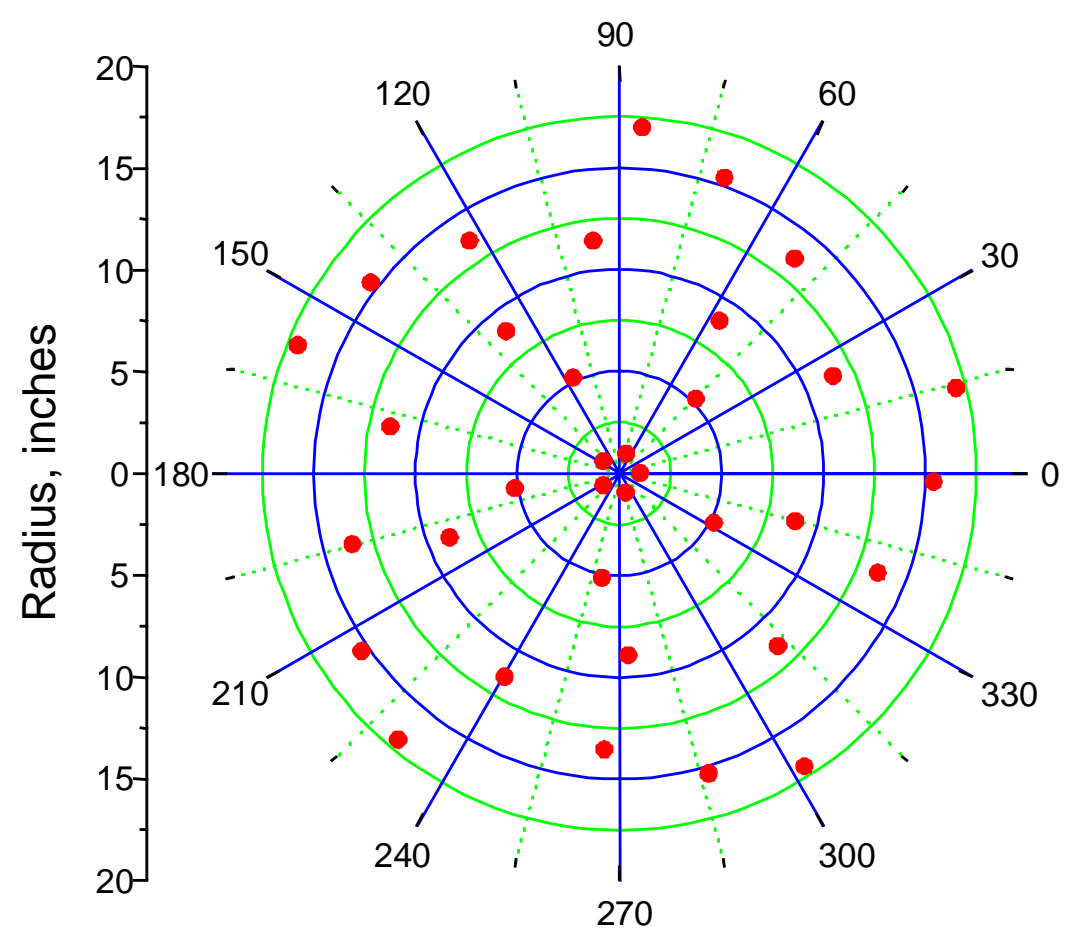

Figure 12. LADA Microphone Locations (Viewed from Front). 


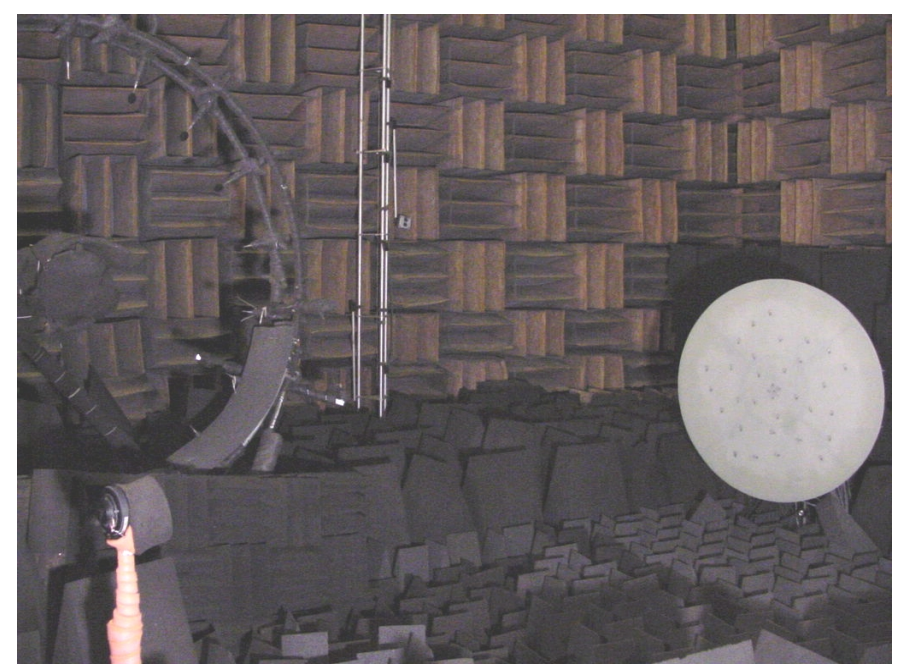

Figure 13. ANRF Point Source / LADA Configuration. Point Source is Located at Lower Left of Image, LADA at Center Right.
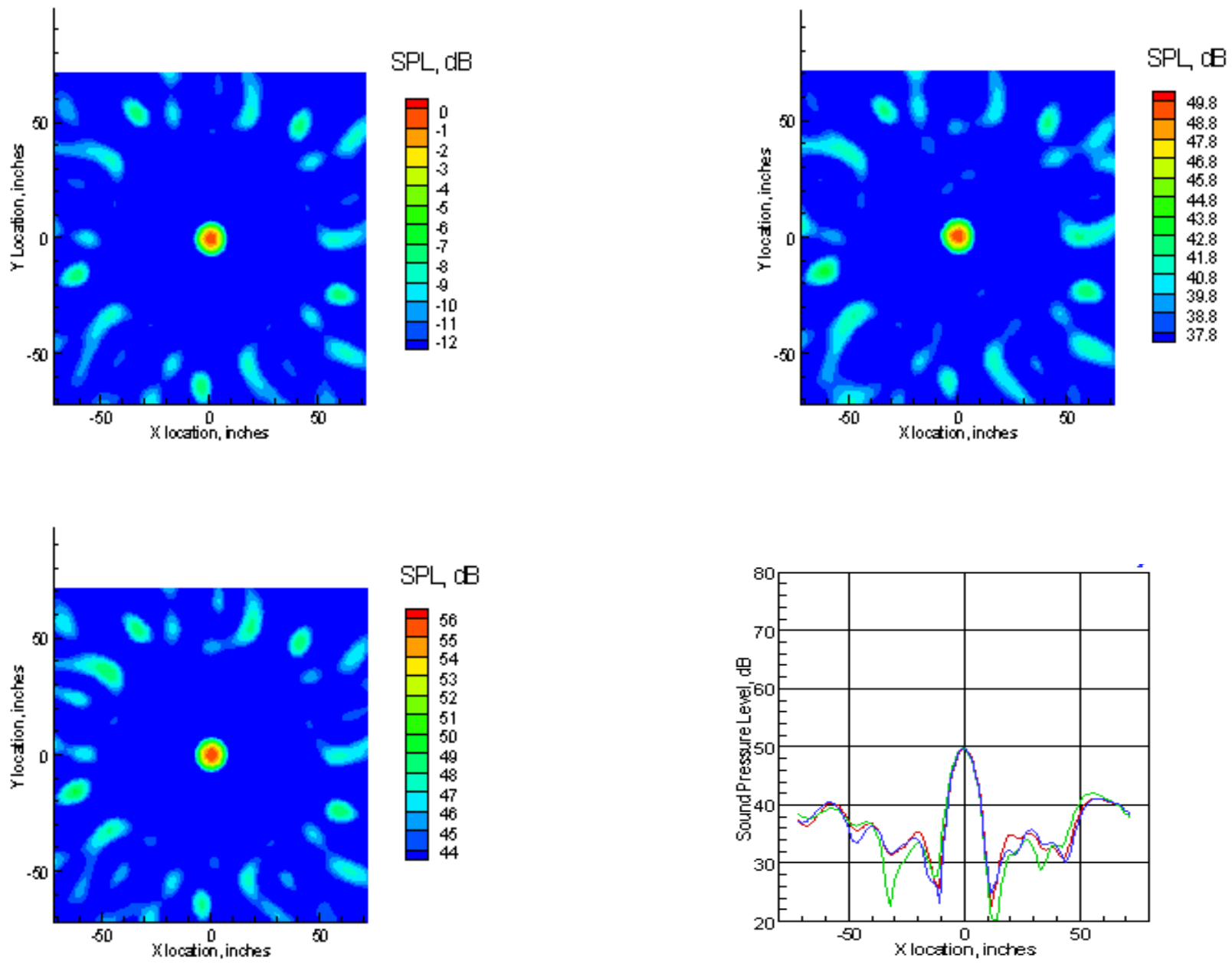

Figure 14. LADA Point Source Run in LaRC ANRF. Source at (0.0, 0.0, 96.0)" wrt Array Center. Upper Left - Theoretical Sidelobe Response for 5-kHz Signal.

Upper Right - Reference LADA Response.

Lower Left - ECM LADA Response.

Lower Right - Horizontal Slice Through Responses (red=theory, green=reference, blue=ECM). 

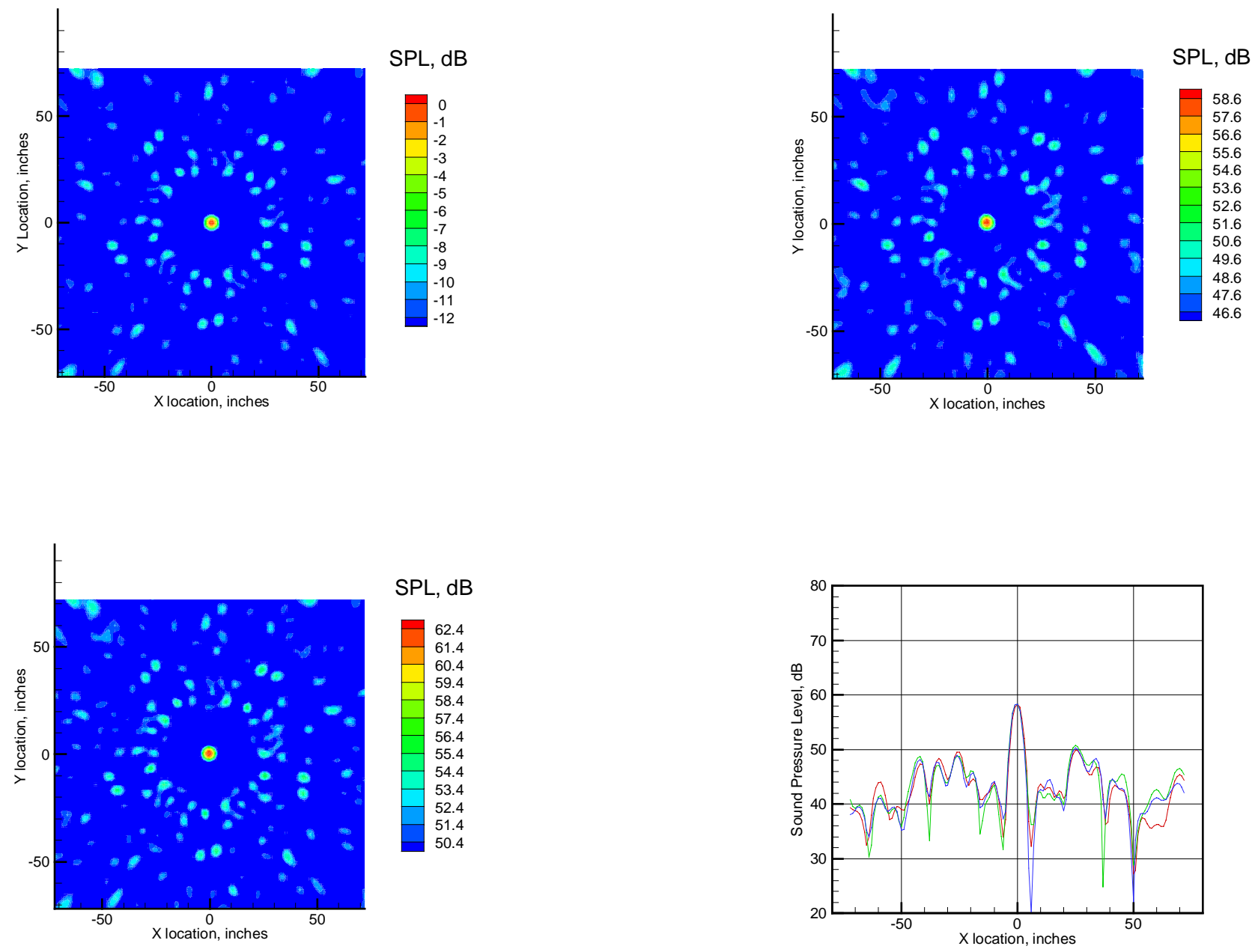

Figure 15. LADA Point Source Run in LaRC ANRF. Source at $(0.0,0.0,96.0)$ " wrt Array Center. Upper Left - Theoretical Sidelobe Response for $10-\mathrm{kHz}$ Signal.

Upper Right - Reference LADA Response.

Lower Left - ECM LADA Response.

Lower Right - Horizontal Slice Through Responses (red=theory, green=reference, blue=ECM). 

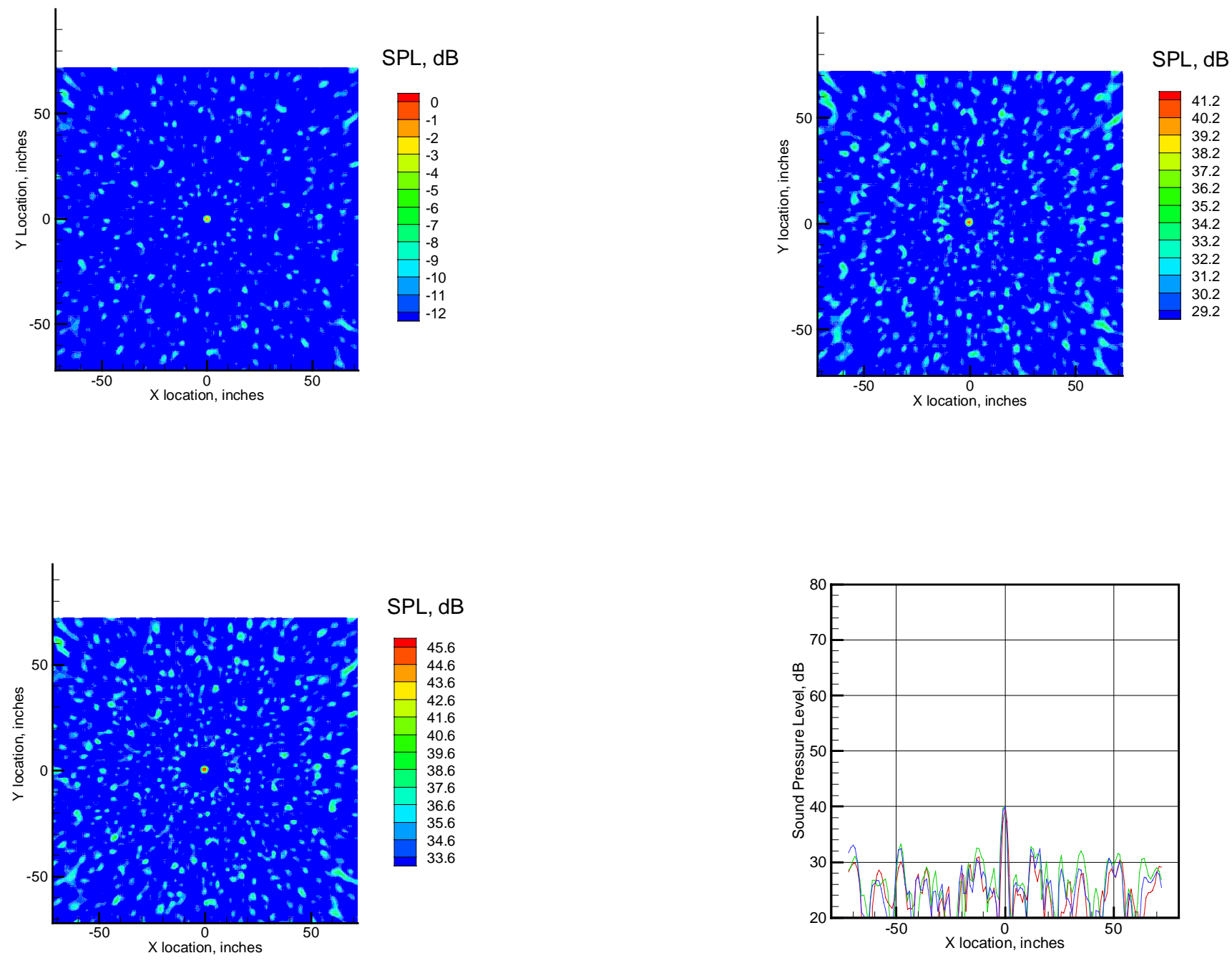

Figure 16. LADA Point Source Run in LaRC ANRF. Source at (0.0, 0.0, 96.0)" wrt Array Center. Upper Left - Theoretical Sidelobe Response for $20-\mathrm{kHz}$ Signal.

Upper Right - Reference LADA Response. Lower Left - ECM LADA Response.

Lower Right - Horizontal Slice Through Responses (red=theory, green=reference, blue=ECM). 


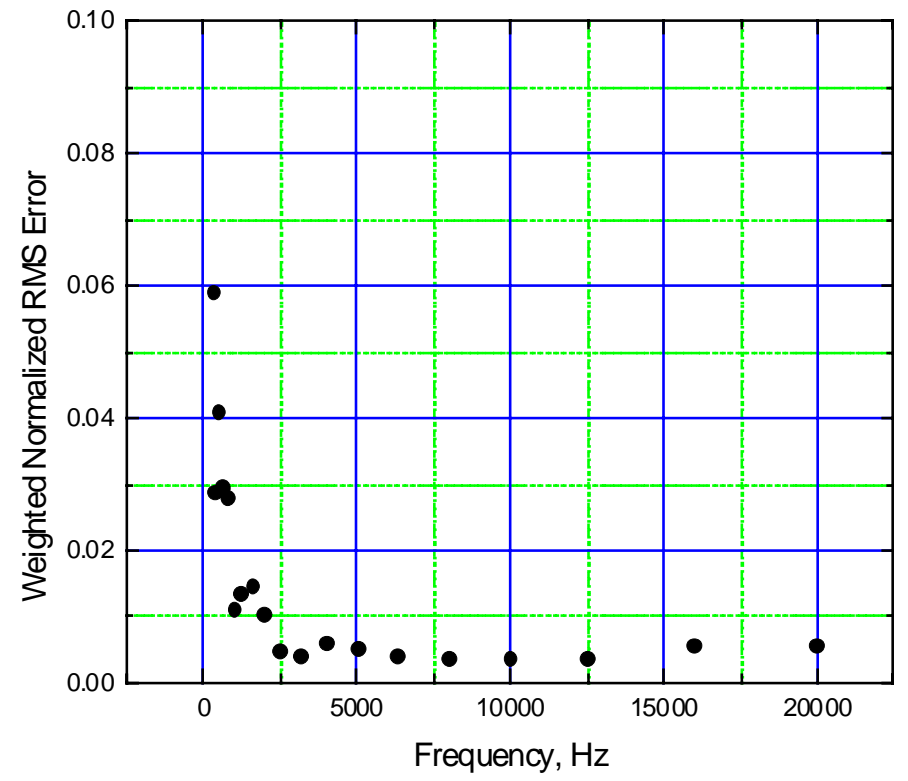

Figure 17. Weighted-RMS Errors Between ECM and Reference LADA Beamformed Output for Single Point Source in LaRC ANRF.

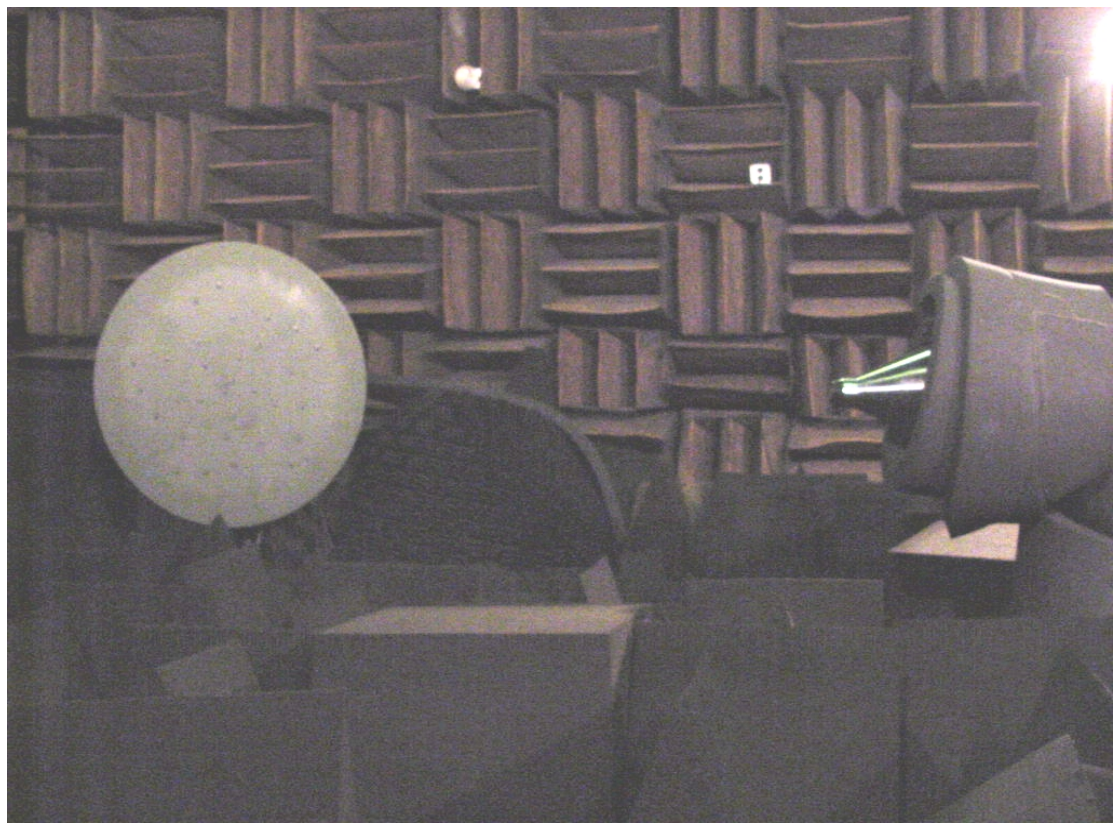

Figure 18. Acoustically Treated Nozzle and ECM LADA in ANRF. 


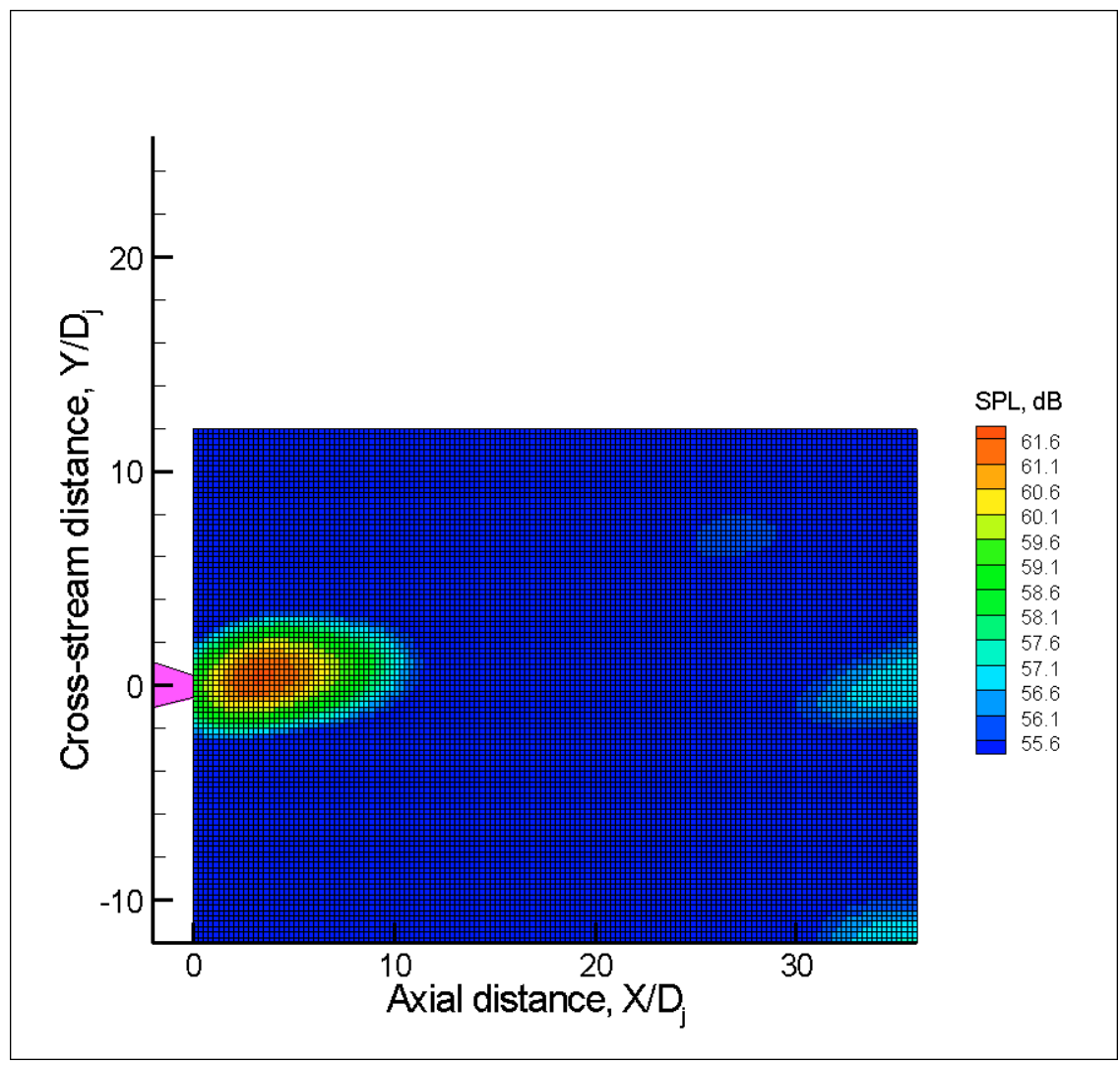

Figure 19. Typical Jet Flow ECM LADA Source Map. $M=0.647$, Frequency=5000 Hz. Steering Grid Overlaid on Map. $D_{j}=2$ inches.

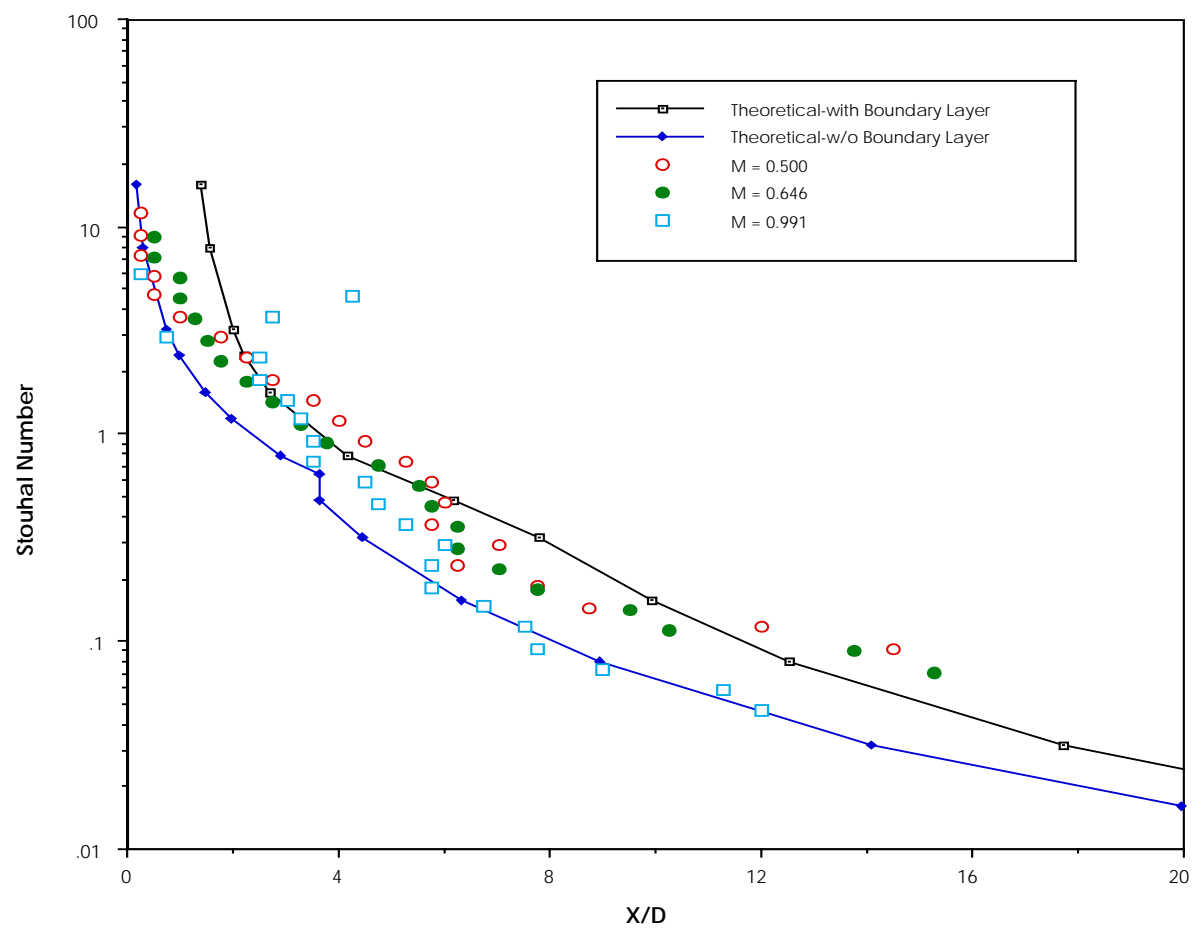

Figure 20. Axial Location of Jet Peak Source Strength for Range of Exit Velocities. 